\title{
A Ama-De-Leite e o Bebê: Reflexões em torno do apagamento de uma face
}

Marco Antonio STANCIK ${ }^{\circ}$

\begin{abstract}
Resumo: O objetivo deste breve ensaio é analisar um retrato fotográfico datado do final do século XIX, onde figuram uma amade-leite e um bebê. Propõe-se que este é também um retrato das desigualdades e contradições presentes nas relações sociais estabelecidas na sociedade brasileira, a partir do qual é possível exemplificar o emprego de fontes fotográficas no trabalho do historiador.
\end{abstract}

Palavras-chave: Fontes historiográficas; Retratos fotográficos; Brasil - Século XIX.

Ao observarmos uma fotografia, devemos estar conscientes de que a nossa compreensão do real será forçosamente influenciada por uma ou várias interpretações anteriores. Por mais isenta que seja à interpretação dos conteúdos fotográficos, o passado será visto sempre conforme a interpretação primeira do fotógrafo que optou por um aspecto determinado, o qual foi objeto de manipulação desde o momento da tomada do registro e ao longo de todo o processamento, até a obtenção da imagem final.

Boris Kossoy (2001: 113)

- Profissional de Ciência e Tecnologia do Instituto Agronômico do Paraná - IAPAR - 84001-970 - Ponta Grossa - Paraná - Brasil. Doutor em História pela Universidade Federal do Paraná - UFPR. E-mail: marcostancik@hotmail.com

HISTÓRIA, São Paulo, 28 (2): 2009 


\section{Introdução}

O Brasil rapidamente aderiu ao modismo da fotografia, desde que aqui chegaram notícias sobre o grande invento datado de 1839, com o qual, acreditava-se, tornara-se possível fixar imagens quase sem a intervenção humana. No país, seu grande incentivador no correr do século XIX foi o imperador D. Pedro II (1825-1891), cujo reinado estendeu-se de 1840 até 1889. Foi ele o primeiro a adquirir e fazer uso de um daguerreótipo espécie de avô da câmera fotográfica.

A partir da constatação do processo de expansão da fotografia no Brasil, concomitante ao seu aperfeiçoamento técnico e barateamento, diversos autores falam de uma possível "democratização" ou popularização do hábito de se fazer retratar, o qual teria se acentuado no país ainda antes do último cartel do período oitocentista (FREUND, 1976; MOURA, 1983; LEITE, 2001; KOSSOY, 2001, 2002a; MUAZE, 2006; KOUTSOUKOS, 2006, 2007a). Embora essa expansão tenha ocorrido, propõe-se que não pode ser pensada necessariamente em termos de "democratização", pois constata-se a existência de fatores que a mantiveram inacessível a segmentos da população.

É o que se pretende demonstrar a partir das reflexões suscitadas através da análise de um retrato fotográfico em que figura um bebê e sua provável ama-de-leite. Esta última teve sua face apagada propositalmente, constituindo exemplo extremo de relações sociais desiguais, estampadas em retratos do final do século XIX. ${ }^{1}$ Conclui-se, portanto, que no Brasil existiam outras barreiras ao acesso daqueles artefatos, além daquelas de caráter técnico, ou relacionadas aos seus preços.

\section{O historiador e os retratos fotográficos}

A despeito de nos dias atuais ainda persistir a crença na fidelidade da fotografia, tem-se por pressuposto que, quando se trata de um retrato posado,é inegável que a pose serve para fixar 
A AMA-DE-LEITE E O BEBÊ: REFLEXÕES...

e expor uma teatralização, uma representação de alguém que sabe que está sendo fotografado. De alguém que se aproveita daquela ocasião para mostrar não necessariamente aquilo que é, mas aquilo que deseja que os outros pensem a seu respeito. Quando se trata de um instantâneo, o fotógrafo enquadra, ou seja, escolhe o que irá aparecer ou não, a seu bel prazer. Ele seleciona o que e como fotografar, segundo seu talento, recursos e intenções daquele momento. O mesmo se observa no caso do retrato posado.

Assim sendo, os registros fotográficos devem ser tomados não apenas como uma imagem com a qual se procura captar a realidade, ${ }^{2}$ mas como sua construção e/ou leitura, como manipulações/interpretações (KOSSOY, 2001). Como meio de comunicação através de mensagens de caráter não-verbal e forma de mostrar-se para si e para os outros: durante o ato da pose, o fotografado e o retratista não apenas fixam uma determinada postura, mas selecionam previamente os elementos que irão compor o retrato. Existe, portanto, uma cumplicidade entre ambos.

Realiza-se, desta forma, um trabalho social de produção de sentido, o qual é operado pelo fotógrafo e, não menos, pelo fotografado que faz pose diante da câmera (BARTHES, 1984). Formas de expressão produzidas tendo em vista determinados usos, individuais e/ou coletivos, e que nos revelam pistas sobre diferentes maneiras de pensar, sentir e agir. Formas que não são, necessariamente, correspondentes às daquele que delas se apropria posteriormente (FREUND, 1976; MACHADO, 1984; CARDOSO \& MAUAD, 1997).

Considerada a fotografia como uma imagem e como uma forma de interação social e de comunicação, tem-se por pressuposto que seu significado mais profundo não se encontra necessariamente explícito, pois é imaterial, apesar do "realismo fotográfico da aparência" de que ela se reveste (KOSSOY, 2001: 117). Comunicação que não se realiza pela linguagem verbal do fotografado, mas, no caso de retratos, como se trata no presente estudo, através de outras formas de expressão: a corporal, a gestual, entre outras. Busca-se, portanto, identificar seu 
conteúdo e, além disso, deduzir, ao menos parcialmente, o que não está visível, ou seja, as articulações do conteúdo interno com o externo às fotografias (LEITE, 2001: 44; KOSSOY, 2001).

Sendo assim, toma-se o retrato fotográfico como um produto social e cultural, concebido como documento e como monumento. Como registro, um fragmento que chega até nós oriundo de outros tempos, e como recurso apto a comunicar representações, ou seja, modos pelos quais indivíduos e grupos sociais representam a si e ao mundo. Representações elaboradas cultural/estética/tecnicamente (KOSSOY, 2002b), mais evidentes quando fixadas em retratos de corpo inteiro, valorizando a pose. Conforme proposto por Ana Maria MAUAD, reportando-se às reflexões do historiador francês Jacques LE GOFF:

...parafraseando Jacques Le Goff, há que se considerar a fotografia, simultaneamente como imagem/documento e como imagem/monumento. No primeiro caso, considera-se a fotografia como índice, como marca de uma materialidade passada, na qual objetos, pessoas, lugares nos informam sobre determinados aspectos desse passado - condições de vida, moda, infraestrutura urbana ou rural, condições de trabalho etc. No segundo caso, a fotografia é um símbolo, aquilo que, no passado, a sociedade estabeleceu como a única imagem a ser perenizada para o futuro. Sem esquecer jamais que todo documento é monumento, se a fotografia informa, ela também conforma uma determinada visão de mundo. (MAUAD, 1996: 80) ${ }^{3}$

Sem esquecer, não menos, que, mesmo muito tempo após realizada, ela segue sendo interpretada, oscilando os seus significados. Afinal, a fotografia, seja em sua produção, seja em sua recepção, sempre dá margem a um processo de construção de realidades (KOSSOY, 2002b: 42).

Compreendendo-se que tais formas de comunicação nãoverbal empregadas para transmitir mensagens apresentam diferentes significados em diferentes sociedades e culturas, contextos e/ou períodos, circunstâncias e situações, são elas analisadas através do método iconográfico/iconológico proposto por KOSSOY (2001, 2002b). Ou seja, a partir de sua inserção e em 
A AMA-DE-LEITE E O BEBÊ: REFLEXÕES...

contraponto com o contexto histórico em que foram produzidas; mediante o confronto entre o global e os pormenores (LEITE, 2001: 158), entre aqueles fragmentos e seu contexto mais amplo, entre o privado (o retrato de família) e a esfera pública.

Pretende-se, ao mesmo tempo, contribuir para minimizar algumas lacunas. Uma delas foi observada por Miriam Moreira LEITE (2001: 79), segundo a qual "raramente se tentou a análise de uma fotografia isolada", sem dedicatória, identificação, data precisa. Por isso, diante da inexistência de mais detalhes a respeito da fotografia e dos retratados, uma via possível para a análise é buscar explorar na imagem aquilo que ela pode nos revelar de simbólico. Busca-se assim inseri-la no panorama sócio-cultural no qual foi produzida, suas redes de significações e os códigos convencionais da sociedade que lhe deu origem (MAUAD, 1990). ${ }^{4}$

A outra lacuna é a ausência de estudos focados em fotografias similares, isto é, nas quais uma face foi intencionalmente ocultada. ${ }^{5}$

Pretende-se, portanto, tornar historicamente significativa a fotografia da ama-de-leite sem rosto. Não para contar a história de determinada família, ou indivíduo, mas para pensar as relações sociais e culturais que permearam e tornaram possível, desejável e aceitável tal tipo de expressão iconográfica, da qual existem, seguramente, muitos outros exemplos, além daquele aqui analisado.

\section{A ama-de-leite e o bebê no estúdio fotográfico}

No Brasil das décadas finais do século XIX, a fotografia, em sua função simbólica de representação individual e familiar, estava totalmente popularizada entre as práticas dos mais abastados (MUAZE, 2006: 90). Procedimento no qual eram emulados pelas classes menos privilegiadas, até mesmo por exescravos. Além do desejo de perpetuar a própria imagem, se fazer fotografar era um gesto através do qual se pretendia demonstrar prestígio social, status, respeitabilidade (FABRIS, 
1998; KOUTSOUKOS, 2006). Os retratos, destaca Solange Feraz de LIMA (In: FABRIS, 1998: 61), constituíram assim "o gênero mais comercializado da fotografia no século XIX".

Corresponde este ao momento de produção do retrato fotográfico aqui reproduzido. Então, constituía ele um retrato de um bebê. Como observa KOUTSOUKOS (2005, 2006, 2007a), se em imagens similares era inegável a presença da ama, nem por isso elas deixavam de ser percebidas como retratos de crianças. Apenas mais recentemente, talvez por obra de colecionadores e/ou pesquisadores de fotografias, passaram a ser enquadradas na categoria de "retratos de amas-de-leite".

Ama e bebê nos permitem perceber que, se a fotografia é uma teatralização, mais que simplesmente nos informar sobre a aparência das pessoas, roupas, casas e paisagens, ela nos dá pistas sobre modos de ser, pensar, sentir e agir de outros tempos. Alguns deles ainda hoje presentes. Passemos, então, a explorar a imagem, para, em seguida, abordar parte daquilo que ela pode nos dizer.

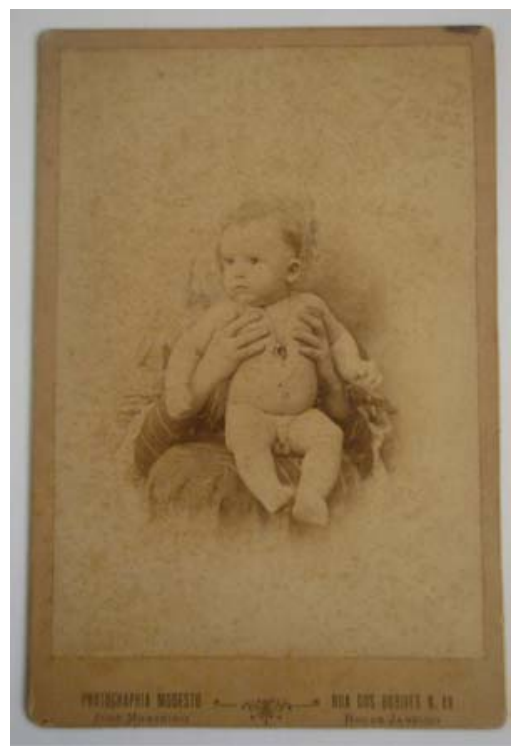

664
FIGURA 1: Ama-de-leite com bebê. Photographia Modesto (José Monteiro), Rio de Janeiro, 1895-1896. Cabinet portrait, 14,0 x $9,5 \mathrm{~cm}$.

FONTE: Coleção do autor.

HISTÓRIA, São Paulo, 28 (2): 2009 
A AMA-DE-LEITE E O BEBÊ: REFLEXÕES...

Entre os anos de 1895 e 1896, o fotógrafo José Monteiro manteve na cidade do Rio de Janeiro um estúdio, a Photographia Modesto, situado na Rua dos Ourives, número 69, antigo 77. Ao lado da Rua do Ouvidor, a dos Ourives está localizada no coração da cidade, onde se concentrava o comércio mais requintado do período. Tratava-se de endereço tradicional, onde já haviam se instalado outros profissionais do ramo. Um deles foi Adolpho Aragonez de Faria, que ali permaneceu entre 1887 e 1894. Antes dele, desde o ano de 1867, atuou no local o premiado Modesto Augusto da Silva Ribeiro, cujo nome ficou associado ao endereço, mesmo após ter deixado de utilizá-lo (KOSSOY, 2002a: 129-130, 272-273).

Muitos eram os concorrentes de José Monteiro com destaque no cenário fotográfico da cidade do Rio de Janeiro, devido ao reconhecimento profissional e social obtidos. Cada um com suas características individuais, ou seja, com sua marca individual (LIMA \& CARVALHO, 1997: 29), que singularizavam sua produção. Entre outros, Joaquim Insley Pacheco, José Ferreira Guimarães, Marc Ferrez. Visinho do estúdio Modesto, Pacheco ostentava o título de fotógrafo oficial da Casa Imperial, condição que lhe possibilitou tornar-se autor de inúmeros retratos de seus membros. Isso fazia dele um profissional a serviço de uma clientela melhor aquinhoada, sendo apontado por KOSSOY (2002a: 247) como um dos mais afamados retratistas brasileiros.

José F. Guimarães, que por certo período manteve estúdio na Rua dos Ourives, também era fotógrafo da Casa Imperial, tendo acumulado considerável fortuna. Marc Ferrez, além de talentoso retratista, inclusive da família imperial, bem como daqueles que acorriam ao seu estúdio, extrapolou aqueles limites para tornar-se um dos maiores fotógrafos de cenas urbanas e rurais, aspectos do cotidiano e tipos humanos (negros e indígenas) de sua época (KOSSOY, 2002a: 134-139, 167-168). Grande parte desse trabalho, realizado em lombo de burro, recurso indispensável no transporte dos pesados equipamentos através das estradas poeirentas. 
Evidentemente, não era apenas na cidade do Rio de Janeiro que proliferavam os estúdios. Por todo o país, a partir da década de 1840, ocorreu uma expansão daqueles profissionais, que chegavam a todos os cantos do país, instalando estúdios, ou como fotógrafos itinerantes. Para ficar apenas na cidade de São Paulo, cabe destacar Militão Augusto de Azevedo, proprietário da Photographia Americana, onde produziu retratos de personagens oriundos dos mais variados extratos sociais, indo "do imperador ao escravo, do militar ao funcionário público" (KOSSOY, 2002a: 68), e assim por diante.

Também da autoria de Militão, o Álbum comparativo da cidade de São Paulo (1862-1887) teve por objetivo registrar as transformações urbanas sofridas pela cidade naquele intervalo de tempo. Isso o fez retornando, 25 anos após, aos mesmos locais registrados em 1862, para fotografá-los sob o mesmo ângulo.

Contudo, para obter sucesso naquela arte, não bastava apenas revelar talento. $\mathrm{Na}$ intenção de atrair a clientela desejosa de se retratar, os profissionais da área esmeravam nos anúncios em jornais e na organização de seus estúdios. Segundo KOUTSOUKOS (2006: 21):

Nas paredes das salas de espera dos estúdios, eram expostas fotos emolduradas; nos móveis, álbuns mostruário. Quem tinha feito retrato de alguma personalidade, o colocava em local de destaque. Nas fotos da sala de espera, o cliente deveria se inspirar, procurando a sua representação ideal; mas toda aquela exposição também advertia o interessado sobre a qualidade do trabalho do estúdio.

O objetivo era um só: a obtenção de boas fotografias e a consequente satisfação do cliente. "Tudo ali reunido serviria para distrair das preocupações a alma do visitante e dar ao seu rosto uma expressão de calma e felicidade, que seria registrada na fotografia" (KOUTSOUKOS, 2006: 21).

Naquele contexto, um certo dia, o estúdio de José Monteiro recebeu a visita de um casal que se fazia acompanhar por um 
A AMA-DE-LEITE E O BEBÊ: REFLEXÕES...

bebê de poucos meses de idade e de sua babá. Esta última, provavelmente servia-lhe também como ama-de-leite. ${ }^{6}$ Se assim se passava, ela tinha por missão não apenas cuidar da criança, como amamentá-la, até o momento em que seu organismo estivesse em condições de receber outros tipos de alimentos. Esses serviços eram procurados porque a mãe não desejava ou não estava em condições de amamentar.

No correr do século XIX, segundo relatos de viajantes europeus, entre as classes abastadas brasileiras o emprego de amas-de-leite representava, além do mais, uma forma de distinção social. Isso explica o fato de muitas delas figurarem em fotografias exibindo trajes requintados, provavelmente cedidos por suas proprietárias.

Embora o seu emprego tendesse a escassear ao final do período oitocentista, ainda nas primeiras décadas do século seguinte era comum encontrar anúncios em jornais oferecendo tais serviços. Quando já estavam mais crescidas, não raras vezes as crianças continuavam sob os cuidados da ama, agora na condição de "ama-seca".

Até a abolição da escravatura, decretada em 1888, era comum negras escravizadas, pertencentes à família, ou alugadas, servirem como amas-de-leite. Para que o leite e a atenção da ama fossem dedicados exclusivamente à criança pela qual ela se tornava responsável, costumava-se afastá-la de seus filhos naturais.

Quando os pais do bebê dirigiram-se ao estúdio fotográfico de José Monteiro, o objetivo era fazer um ou mais retratos da criança. Estes provavelmente iriam compor seu álbum de família, hábito já amplamente popularizado na Europa, e que, no Brasil, também encontrava grande aceitação entre os círculos abastados. Produzidos no formato cabinet-portrait, cópias do retrato deveriam ainda ser distribuídas a amigos e parentes, como tornara-se hábito desde a segunda metade do século XIX, ou seriam exibidas em porta-retratos, entre outros possíveis usos a que poderiam se prestar.

A fotografia de estúdio, trabalho produzido por um profissional, como a que estamos tratando, é descrita por 
KOSSOY (2001: 110-111) como um "ato fotográfico teatral", cujo personagem central é o próprio retratado, ao passo que o fotógrafo desempenha os papéis de diretor da peça, iluminador e contra-regra. O ambiente criado nos estúdios era, em regra, composto por móveis rebuscados, entalhados, repletos de detalhes e objetos os mais variados. Estes podiam ir de um livro, emprestando ao fotografado um ar intelectualizado, a animais, empalhados ou não.

Artifícios teatrais para uma auto-representação que situavam o retratado "longe do indivíduo e perto da máscara social" (FABRIS, 1998: 21). Recursos que tinham o objetivo de realçar determinadas características do fotografado, fossem elas reais ou fictícias, servindo de cenário para a representação. ${ }^{7}$ Como bem observou KOSSOY (2001: 105), as fotografias do passado, em especial as do século XIX, "mostram assuntos geralmente bem-organizados em sua composição e aprioristicamente petrificados, antes mesmo do congelamento fotográfico".

Os recursos empregados no estúdio, a pose, o olhar, o cenário, serviam para fixar, de antemão, uma representação. Para compreender e exemplificar como isso se passava, vejamos como se deu o trabalho de realização do retrato fotográfico da ama e do bebê.

O arranjo formal de um dos retratos produzidos naquele dia e ainda hoje existente, contando agora mais de 100 anos, mostra-nos, ao centro, um bebê totalmente nu, do sexo masculino, branco, aparentemente saudável, aparentemente bem alimentado. A criança traz algo pendurado ao pescoço, provavelmente um amuleto preso a um cordão. Conforme já observara o pintor francês Jean Baptist Debret (Apud LEITE, 2001: 29), no início do século XIX, quando esteve no Brasil, era hábito fazer os bebês portarem talismãs e amuletos, como recurso para proteção contra possíveis feitiços, bruxarias e o mal-olhado.

No retrato, o bebê está no colo e é sustentado - em todos os sentidos que a noção comporta - por uma mulher que permanece sentada, exibindo trajes escuros, que ajudam a 
A AMA-DE-LEITE E O BEBÊ: REFLEXÕES...

destacar a silhueta muito clara da criança, em relação ao fundo do cenário. Embora pouco possa ser observado, não seria de todo improvável que suas vestes revelassem inspiração africana, assim como é pouco provável que se trate de trajes que remetam à moda européia, como repetidas vezes se constata em retratos de indivíduos pertencentes tanto às classes abastadas, como às menos favorecidas.

Observe-se ainda que, divergindo da tendência então predominante, o retrato do bebê foi realizado sem o emprego de recursos cenográficos. Tal fato constitui uma evidência da intenção de centrar sobre o mesmo a atenção daqueles que focassem a imagem.

A composição do retrato revela o desejo de expor algo de forma ostensiva e inequívoca: a criança é exibida pela ama, como se fosse um troféu. Um troféu que não lhe pertence, mas a mantém presa a uma família que não é a sua. Os pais estão felizes e orgulhosos com seu belo bebê! $E$ mostram de forma inquestionável que se trata de um menino! A exibição da criança não deixa de ser, ao mesmo tempo, uma forma de expressar, provar e exaltar a consumação do matrimônio, a virilidade masculina e a fertilidade feminina. Era um retrato que apresentava, entre outras funções, a de reiterar a continuidade da linhagem familiar, conforme destacou Nelson SCHAPOCHNIK (2006: 480), ao analisar outros retratos do período.

Além disso, se fosse uma família de posses, o que parece plausível, ali estava personificada a esperança de assegurar não apenas a continuidade do sobrenome, assim como dos negócios, ou, talvez, da profissão de seu pai. Isso se atingisse a idade adulta, sobrevivendo às enfermidades e outras vicissitudes que alimentavam as taxas de mortalidade infantil do período. ${ }^{8}$

Quanto à identidade dos retratados, permanece ignorada, pois, em nenhuma das faces da fotografia foi acrescentada qualquer anotação detalhando o nome da criança, da ama, ou de seus pais, ou qualquer outra informação a respeito.

Percebe-se que, durante o cerimonial fotográfico, e estando no colo da mulher que o sustentava, o bebê permaneceu tranqüilo, muito à vontade. Considerando a direção de seu olhar, 
tem-se a impressão que, enquanto aguardavam, os pais devem ter se posicionado à sua frente, à direita, atraindo o seu olhar, tranqüilizando-o e desviando-lhe a atenção do estranho, o qual estava encarregado de fazer o seu retrato da melhor maneira possível. Este último, servindo-se da parafernália disponível no seu estúdio, encarregava-se do vai e vem necessário para ajustar a pose de seu modelo, o bebê.

Como também se observou nos retratos analisados por KOUTSOUKOS $(2006,2007 b)$, a organização formal do trabalho realizado no estúdio da Photographia Modesto nos remete às tradicionais imagens das Madonas, ou seja, das pinturas que buscavam retratar a Virgem Maria com seu filho ao colo. E isso estava em sintonia com os padrões adotados na Europa para a produção de retratos fotográficos, nos quais eram seguidos, na medida do possível, os cânones há muito adotados na pintura (FRIZOT, 1998).

Contudo, o detalhe que mais chama a atenção aos olhos de quem hoje contempla o retrato é o apagamento intencional da face da ama-de-leite que fez pose como uma Madona. Isso foi obtido pelo fotógrafo através do efeito flou, com o qual se valorizava a figura do retratado (neste caso, fica evidente que se tratava somente do bebê), esvanecendo suavemente o cenário ao seu redor. E assim se excluiu por completo qualquer sinal da face da ama. Talvez isso tenha sido feito por sugestão do fotógrafo. Talvez a pedido dos pais que contrataram seus serviços. O fato é que houve acordo entre ambos em favor do apagamento e se acredita ser pouco provável que o fizeram a pedido da ama.

Conforme observa Cândido Domingues GRANGEIRO (1998), analisando a produção do fotógrafo Militão Augusto de Azevedo, a realização de um retrato fotográfico pressupõe uma prévia negociação entre o contratante e o profissional. Ou seja, entre os desejos e expectativas do fotografado e os recursos, conhecimentos e habilidades do retratista. E assim, constata-se que foram numerosos os registros fotográficos de amas e bebês, nos quais se tentou passar uma imagem de afeto e carinho. ${ }^{9}$ Seguramente, tal arranjo era devido a um prévio acordo entre os 
A AMA-DE-LEITE E O BEBÊ: REFLEXÕES...

pais do bebê e o fotógrafo, o que resultava na produção de uma imagem favorável de ambos os retratados.

Caminhando em outra direção, o "detalhe" do apagamento revela que o retrato produzido no estúdio Modesto, que hoje classificamos como de uma ama, não lhe era destinado, e que, mesmo assim, ela representou da melhor maneira possível o papel da ama-de-leite. Para tanto, fez pose como se fosse uma Madona e manteve a criança tranqüila, de forma a viabilizar uma imagem positiva do bebê sob os seus cuidados.

Esse mesmo detalhe expressa, ainda, que o "modesto" presente na denominação do estúdio fotográfico era apenas uma referência ao sobrenome de seu primeiro e afamado proprietário. Nem por isso era um espaço para representações de modéstia. Como também não o eram os demais estabelecimentos fotográficos. Afinal, mesmo os membros das classes menos abastadas que o procuravam voluntariamente - o que não parece ser o caso da ama-de-leite - desejavam ser retratados de forma distinta. Inclusive ex-escravos, que assim demonstravam estar à procura de afirmação social, em conformidade e reafirmando padrões e valores da sociedade burguesa, pois, conforme Annateresa FABRIS (2004: 40), a sociedade do século XIX conferiu à imagem fotográfica o papel de atestado de uma existência.

\section{$O$ retrato em seu contexto}

Tentando compreender as possíveis motivações para a produção de retratos de bebês e amas-de-leite, KOUTSOUKOS $(2005,2006,2007$ a) propõe que o carinho, a gratidão, o afeto poderiam ser uma explicação para tal gesto. Hipótese mais provável no caso daquelas que fossem reconhecidas como "boas amas".

No retrato em questão, a afinidade entre os retratados parece se comprovar pelo fato do bebê ter permanecido muito à vontade no colo da ama. E assim, pode-se manter a suposição 
desta última ser considerada uma "boa ama", que viria o acompanhando, talvez, desde o seu nascimento.

Contudo, não se tratava de um retrato encomendado para demonstrar qualquer tipo de reconhecimento pelos bons serviços prestados pela ama. Fosse assim, seu rosto não seria submetido ao ocultamento obtido através do emprego do efeito flou. Mesmo porque essa não era a regra adotada para a produção de semelhantes retratos. Ao contrário disso, são mais numerosos os exemplos de fotografias em que a face da ama permaneceu visível.

Os manuais de fotografia do século XIX, período em que a pose tornou-se o símbolo da fotografia (TURAZZI, 1995: 13), informavam que os pontos de maior destaque do modelo a ser retratado deveriam ser o rosto e as mãos (FABRIS, 1998; KOUTSOUKOS, 2007b: 7), dando a impressão de status e respeitabilidade. Tal regra possivelmente era observada mesmo nos retratos das amas, quando se optava por não esconder seu rosto. Logo, se constata que a ama do retrato em questão não estava destinada a figurar, exceto nos detalhes cujo apagamento foi considerado inconveniente.

Portanto, é gritante o contraste entre a suavidade do efeito flou, truque com o qual se obtinha interessantes e belos efeitos estéticos nos retratos fotográficos, e a rudeza do seu emprego para ocultar a face da ama, como se ela não passasse de um mero objeto presente no cenário. E foi exatamente esse o papel por ela desempenhado: o de um objeto destinado a viabilizar a pose. Ou seja, pode-se afirmar que a ama cumpriu papel similar ao de um apoio para a imobilização da cabeça e do tronco. Objetos estes empregados para favorecer a imobilidade de adultos e crianças maiores, durante a realização do retrato, e que não deveriam ser percebidos nas fotografias. Ou seja, que deveriam apenas contribuir para a pose, mas sem aparecer na imagem obtida.

Produzidos em madeira e ferro, os apoios foram muito utilizados pelos primeiros fotógrafos, embora no final do século XIX estivessem em desuso, pelo menor tempo de exposição então necessário para a obtenção de uma fotografia. Impossível 
A AMA-DE-LEITE E O BEBÊ: REFLEXÕES...

de ser aplicado a um bebê, tal apoio era, em determinadas ocasiões, substituído pela presença da ama.

Assim, em termos de relações sociais, devemos nos questionar o que pode ter significado o apagamento do rosto, como se deu com a ama do retrato. Podemos compreender semelhante gesto somente se o tomarmos como um produto e expressão das relações estabelecidas entre as elites e as classes pobres e das desigualdades que marcavam a sociedade brasileira de então, branca e racista, fundada na escravização do negro e na desqualificação do trabalho por eles realizado. ${ }^{10^{3}}$

Assim como a ama parcialmente apagada do retrato fez com o bebê, trata-se de homens e mulheres que literalmente sustentaram a economia de um país e uma sociedade que não lhes pertencia e não lhes dava qualquer espaço e/ou oportunidade. Que deles fez uso enquanto se revelaram úteis como braços para o trabalho, para em seguida fazer o possível para descartá-los.

Aliás, e aqui vai uma suposição, o retrato parece revelar o emprego de outro truque fotográfico muito popular e revelador daquele período: trata-se do clareamento da pele do retratado. É o que possivelmente se observa quando se contempla as mãos muito lisas da ama, caracterizadas pela ausência de detalhes, tais como as veias aparentes e outros sinais típicos de mãos acostumadas ao trabalho duro. Aqueles sinais, assim como sua cor, teriam sido atenuados, fazendo eco ao desejo então imperante naquele final de século de "branquear" o país. Ou seja, o desejo de que viesse a ser habitado somente por "brancos", preferencialmente europeus.

Desta forma, muito ingenuamente, alguns segmentos das classes dominantes e letradas pretendiam fazer do Brasil um país civilizado, o que significava torná-lo capaz de desenvolver uma economia sob os moldes capitalistas. Isto é, ao proporem o "branqueamento", manifestavam o desejo de substituir os negros, "libertos" da escravidão no ano de 1888, por trabalhadores europeus "brancos". Com o crescente incremento de emigrantes brancos no Brasil e através de seu "cruzamento" com negros e mulatos, esperava-se tornar viável o clareamento, 
isto é, o "branqueamento" da pele da população brasileira. E assim, imaginavam alguns intelectuais, seriam aprimoradas suas características físicas, morais e intelectuais.

Constata-se que o fim das instituições escravistas e imperiais, esta última através da implantação da República, em 1889, não se fizeram acompanhar pela extinção dos valores vigentes naquele período. Contexto em que os negros recémlibertos e mulatos passaram a ser percebidos como um estorvo que deveria ser eliminado em favor da construção daquela suposta civilização em moldes europeizados. ${ }^{11}$

Outra hipótese que pode ser aventada para o tratamento dado à ama no retrato, igualmente sintonizada com os ideais de civilização e progresso daquele período, guarda relação com o discurso médico então vigente. Segundo este, a amamentação dita mercenária seria prejudicial à criança, pois aquela que lhe oferecia o leite poderia, ao mesmo tempo, transmitir-lhe doenças. Isso, quando não estava presente o receio de que, através do seu leite, a criança incorporasse supostas "doenças morais", que alguns médicos atribuíam aos negros e mulatos (KOUTSOUKOS, 2006).

Neste caso, no período em que o retrato foi produzido, com a ama sem a face e com as mãos aparentemente embranquecidas, não se deixava margem para especulações em torno do suposto legado negativo que a criança poderia receber por intermédio daquela que se encarregava de seu sustento. Portanto, e com base no discurso médico daquele final de século, o aleitamento dito mercenário era percebido como nocivo. Por isso, tal procedimento, ou sua alusão em uma fotografia, tendiam a ser apontados como práticas atrasadas e que deveriam ser combatidas.

O emprego do efeito flou não atendeu, portanto, apenas a ditames de caráter estético, pois cumpriu outras finalidades sociais, ao ocultar, na imagem fotográfica, um agente social tido como imprescindível - na criação e alimentação de uma criança, bem como no momento de captar sua imagem -, contudo, malvisto ao final do século XIX, posto que associado a um 
A AMA-DE-LEITE E O BEBÊ: REFLEXÕES...

passado considerado "atrasado" e incivilizado, pois tingido pela cor negra dos africanos escravizados.

Nos dias atuais, além das conseqüências já comentadas, o emprego do efeito flou torna praticamente impossível afirmar sequer se a ama era uma jovem, ou se sua idade era avançada, quando compareceu ao estúdio da Photographia Modesto.

De qualquer forma, fica evidente que o retrato não fora produzido para presenteá-la. Ele é um artefato datado histórica e culturalmente. Produto característico da sociedade brasileira do final dos anos 1800, expressão de valores, ideologias, visões de mundo então vigentes. "A identidade do retrato fotográfico", adverte FABRIS (2004: 55), "é uma identidade construída de acordo com normas sociais precisas".

\section{Considerações finais}

Você não fotografa com a sua máquina. É a coisa mais subjetiva que existe. Você fotografa com toda a sua cultura, com os condicionamentos ideológicos. Você aumenta, diminui, deforma, deixa de mostrar.

Sebastião Salgado ${ }^{12}$

Constata-se que a categoria do retrato analisado, assim como todas as possíveis mensagens por ele transmitidas, dependem daquele que lhe dirige a atenção, procedendo a sua leitura. Assim sendo, quando da sua produção, tratava-se de um retrato de um bebê. Artefato com o qual sua família pretendia participar aos amigos e parentes a chegada de um filho do sexo masculino, registro no qual tornara-se conveniente desconsiderar a presença da ama.

Não se tratava, portanto, de uma forma de expressar e registrar carinho e/ou gratidão pelos préstimos da ama. "A fotografia, enquanto produto da técnica", esclarece Solange Ferraz de LIMA (In: FABRIS, 1998: 79), "expõe-se no rol de bens 
da civilização burguesa". Nesse sentido, para a ama, comparecer ao estúdio constituiu apenas mais um momento em que permaneceu no exercício de seu papel. Se ali esteve presente algum tipo de expressão de carinho ou afeto, foi entre esta e o bebê. Aquela expressão iconográfica era uma forma de representação familiar, embora outros membros do mesmo sangue não figurassem. Nela não havia espaço para a ama, exceto nos detalhes que não foi possível ocultar.

Cem anos após, constata-se que o foco da atenção tendeu a se deslocar em favor da ama. Mulher de condição humilde que, ao comparecer ao estúdio fotográfico, foi impedida de representar status e respeitabilidade, conforme era o desejo e a regra daqueles que posavam para um retrato, independente de sua condição social.

Embora sem exibir sua face, ela está lá. A intensidade de sua presença é atestada por suas mãos, o punctum daquele retrato, para nos servirmos de expressão empregada por BARTHES (1984). Elas não apenas seguram firmemente o bebê, como teimam em anunciar sua existência, seu papel importante papel, embora não mais percebido como legítimo -, e a força do vínculo estabelecido entre ambos.

Ao sustentar o pequeno menino para a realização do seu retrato, é como se, simbólica e paradoxalmente, a ama nos contasse sua história. Uma história que remete às contradições, dilemas e conflitos que permearam as relações sociais tecidas entre homens brancos e livres, de um lado, e negros, mulatos, escravos e ex-escravos, de outro. É um retrato que remete a distintos pertencimentos sociais - o da ama e o do bebê - e suas íntimas e profundas relações, as quais por vezes podiam conduzir ao afeto, mas que assim mesmo incluíam uma carga muito grande de violência, senão explícita, no mínimo simbólica. O retrato, ocultando sem conseguir suprimir, faz uma metáfora de tal situação.

Mesmo sendo-lhe negado mostrar-se, a imagem fotográfica da ama, expressa com intensidade por suas mãos, é, nos termos de Annateresa FABRIS (1998), o seu "atestado de existência", a expressão do seu ser social. Assim sendo, podemos propor que a 
A AMA-DE-LEITE E O BEBÊ: REFLEXÕES...

democratização do acesso à fotografia, ocorrida no Brasil, à exemplo da Europa e dos Estados Unidos, apresenta nuances que se revelam, por exemplo, através de retratos como o da ama, realizado na Photographia Modesto.

Se a fotografia era empregada como um recurso para se obter a própria imagem, um "retrato fiel" de si, e, mais que isso, uma representação de si e do mundo, o apagamento da face evidencia a violência cometida contra a ama. E, por extensão, contra os segmentos da sociedade que ela representava e aos quais pertencia. Violência explícita inclusive durante o já corriqueiro gesto de se fazer fotografar. Por mais valiosos que fossem os serviços por eles prestados, como bem evidencia o exemplo da ama, cujo leite garantia a sobrevivência e o bemestar de uma criança com a qual ela não possuía qualquer vínculo de sangue.

O retrato da ama-de-leite sem face é, portanto, um artefato no qual figuram as contradições da sociedade que o produziu. Ambigüidade presente na proximidade física e afetiva e na distância sócio-econômica entre a ama e o bebê. Dois seres unidos por uma relação nascida não pelo afeto, ou pelo parentesco, mas produto de relações sociais desiguais que determinaram, no caso da produção do retrato fotográfico em questão, que se deixasse de lado padrões imagéticos internacionalmente adotados e que faziam dele o "espelho complacente" referido por FABRIS (1998: 21).

Assim, constata-se ainda que, se o bebê não fez pose, seu retrato no colo da ama sem rosto pode expor muito da sociedade que se construiu no Brasil ao longo de sua história. Por isso, um retrato aparentemente inocente como este pode dar lugar a infindáveis especulações sobre os homens e a sociedade que eles produziram. Sobre relações sociais e cultuais historicamente construídas no país onde o leite materno das negras garantiu a existência dos filhos brancos e mulatos de seus senhores. 


\section{Referências Bibliográficas}

BARTHES, Roland. A câmara clara: nota sobre a fotografia. Rio de Janeiro: Nova Fronteira, 1984.

CARDOSO, Ciro F.; MAUAD, Ana Maria. História e imagem: os exemplos da fotografia e do cinema. In: CARDOSO, C. F.; VAINFAS, R. Domínios da história: ensaios de teoria e metodologia. Rio de Janeiro: Campus, 1997.

FABRIS, Annateresa (Org.). Fotografia: usos e funções no século XIX. 2. ed. São Paulo: Editora da Universidade de São Paulo, 1998.

- Identidades virtuais: uma leitura do retrato fotográfico. Belo Horizonte: UFMG, 2004.

FREUND, Gisele. La fotografia como documento social. Barcelona: Gustavo Gili, 1976.

FRIZOT, Michel (Org.). A new history of photography. 2. ed. Milão: Könemann, 1998.

GRANGEIRO, Cândido Domingues. As artes de um negócio: no mundo da técnica fotográfica do século XIX. Rev.. Bras. Hist., São Paulo, v. 18, n. 35, p. 185-206.

KOSSOY, Boris. Dicionário histórico-fotográfico brasileiro: fotógrafos e ofício da fotografia no Brasil (1833-1910). São Paulo: Instituto Moreira Sales, 2002a.

. Fotografia e história. 2. ed. rev. São Paulo: Ateliê Editorial, 2001.

. Realidades e ficções na trama fotográfica. 3. ed. São Paulo: Ateliê

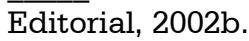

KOUTSOUKOS, Sandra Sofia M. Amas-de-leite no estúdio do fotógrafo: Brasil, século XIX. In: SIMPÓSIO NACIONAL DE HISTÓRIA - ANPUH, 23, 2005. Anais..., Londrina/PR, UEL, jul. 2005, disponível em: <http://www.anpuh.uepg.br/xxiii-simposio>, acesso em: $27 \mathrm{dez} .2008$. . Amas na fotografia brasileira da segunda metade do século XIX. Studium - Representação imagética das africanidades no Brasil. Campinas, 2007a, disponível em: < http://www.studium.iar.unicamp.br/africanidades.html >, acesso em: 18 dez. 2008.

. No estúdio do fotógrafo: representação e auto-representação de negros livres, forros e escravos no Brasil da segunda metade do século XIX. Campinas, 2006. Tese (Doutorado em Multimeios) - Inst. Artes, Universidade Estadual de Campinas. 2 vol. 
A AMA-DE-LEITE E O BEBÊ: REFLEXÕES...

. No estúdio do photographo: o rito da pose (Brasil, segunda metade do século XIX). Agora, Vitória, n. 5, p. 1-25, 2007b, disponível em: <http://www.ufes.br/ppghis/agora>, acesso em: $27 \mathrm{dez} .2008$.

LEITE, Miriam Moreira. Retratos de família: leitura da fotografia histórica. 3. ed. São Paulo: Edit. Universidade de São Paulo, 2001.

LIMA, Solange Ferraz de; CARVALHO, Vânia Carneiro de. Fotografia e cidade: da razão urbana à lógica de consumo: álbuns da cidade de São Paulo (1887-1954). Campinas/São Paulo: Mercado de Letras/Fapesp, 1997.

MACHADO, Arlindo. A ilusão especular: introdução à fotografia. São Paulo: Brasiliense, 1984.

MAUAD, Ana Maria. Através da imagem: fotografia e história interfaces. Tempo, Rio de Janeiro, v. 1, n. 2, p. 73-98, dez. 1996.

. Sob o signo da imagem: a produção da fotografia e o controle dos códigos de representação social pela classe dominante no Rio de Janeiro, na primeira metade do século XX. Rio de Janeiro, 1990. Tese (Doutorado em História) - Progr. Pós-Graduação em História Social, Universidade Federal Fluminense. 2 vol.

MOURA, Carlos Eugênio M. de (Org.). Retratos quase inocentes. São Paulo: Nobel, 1983.

MUAZE, Mariana de Aguiar F. Os guardados da viscondessa: fotografia e memória na coleção Ribeiro de Avellar. An. Mus. Paul., São Paulo, v. 14, n. 2, p. 73-105, jul./dez. 2006.

SCHAPOCHNIK, Nelson. Cartões-postais, álbuns de família e ícones da intimidade. In: SEVCENKO, Nicolau (Org.). História da vida privada no Brasil, 3 (República: da Belle Ėpoque à era do rádio). São Paulo: Cia. das Letras, 2006, p. 423-511.

TURAZZI, Maria Inês. Poses e trejeitos: a fotografia e as exposições na era do espetáculo (1839-1889). Rio de Janeiro: Funarte/Rocco, 1995.

STANCIK, Marco Antonio. The wet nurse and the baby: reflections about the erasure of a face. História, v.28, n.2, p.659682, 2009.

Abstract: The objective of this short essay is to analyses a portrait of the late of $\mathrm{XIX}^{\text {th }}$ century. The portrait presents a wet nurse and a baby. It is believed that the picture may show the inequality and contradictions of social relations in the Brazilian 
society, and exemplify the use of photographic sources in the historical researches.

Keywords: Historical Sources; Photographic Portraits; Brazil XIX th Century.

\section{NOTAS}

${ }^{1}$ O retrato, datado de 1895 ou 1896, pertence à coleção particular do autor e foi adquirido, juntamente com outras fotografias avulsas, através de leilão realizado na cidade do Rio de Janeiro, em outubro de 2008. Nele, além do bebê e das mãos da ama que o sustenta, também são visíveis indicações relativas ao estúdio fotográfico de José Monteiro (Photographia Modesto), localizado na Rua dos Ourives, 69, cidade do Rio de Janeiro, onde foi produzido. Até o momento, não foi possível obter qualquer informação sobre a identidade dos fotografados.

2 Segundo Boris Kossoy, "A imagem fotográfica pode e deve ser utilizada como fonte histórica. Deve-se, entretanto, ter em mente que o assunto registrado mostra apenas um fragmento da realidade, um e só um enfoque da realidade passada: um aspecto determinado. Não é demais enfatizar que este conteúdo é o resultado final de uma seleção de possibilidades de ver, optar e fixar um certo aspecto da realidade primeira" (KOSSOY, 2001: 107).

3 Para a problemática documento/monumento, consultar LE GOFF, Jacques, Documento/Monumento, In: ROMANO, R. (Dir.), Enciclopédia Einaudi, v. 1 - Memória, História. Lisboa, Impr. Nacional/Casa da Moeda, 1984, p. 95-106.

4 Portanto, para o encaminhamento da análise, optou-se pela não adoção do tratamento seriado, o qual, segundo LIMA \& CARVALHO (1997: 15), é habitualmente empregado em estudos de representações sociais.

${ }^{5}$ Foram muitas as fotografias produzidas no Brasil no século XIX, nas quais uma ama-de-leite fez pose junto a um bebê ou criança. Contudo, era menos corriqueiro o apagamento da face da ama no retrato. KOUTSOUKOS $(2006,2007 a)$ faz referência a dois exemplos deste último caso, embora não aprofunde a discussão. Trata-se de trabalhos 
A AMA-DE-LEITE E O BEBÊ: REFLEXÕES...

produzidos anos antes do retrato aqui analisado. Um deles, obra de Militão Augusto de Azevedo, que manteve estúdio na cidade de São Paulo. O outro é da autoria de Alberto Henschel, datado do período em que permaneceu na cidade de Recife.

${ }^{6}$ Conforme observa KOUTSOUKOS (2005) a respeito de tais retratos, a presença de uma mulher que não era a mãe, nem a avó, junto a uma criança tão jovem indicava ser bastante provável que esta última era por ela amamentada. Ao mesmo tempo, a similitude com os dois retratos de amas com a face apagada (KOUTSOUKOS, 2007a) reforça a suposição de o retrato aqui abordado ser também de uma ama.

${ }^{7}$ Para mais detalhes, consultar: LEMOS, Carlos A. C., "Ambientação ilusória" (In: MOURA, 1983: 46-113); TURAZZI (1995), MUAZE (2006), KOUTSOUKOS (2006, 2007b).

${ }^{8}$ O Brasil do oitocentos e início do século seguinte era assaltado continuamente por epidemias de febre amarela, varíola, cólera, peste bubônica, entre outras, além do grande número de doenças endêmicas. Em 1895, provável ano em que o retrato da ama-de-leite foi produzido, ocorreu o célebre episódio do navio italiano Lombardia, que, ao aportar na cidade do Rio de Janeiro com 340 tripulantes, teve 234 mortes ocasionadas pela febre amarela. Naquele final de século e diante do temor das enfermidades, era comum que se aconselhasse aos viajantes europeus para evitar os portos brasileiros. Além destas doenças, as crianças, cuja resistência orgânica tende a ser menor, eram vitimadas também pela disenteria e doenças típicas da infância.

${ }^{9}$ Sobre o assunto, consultar KOUTSOUKOS (2006, 2007a).

${ }^{10} \mathrm{E}$ ampla a bibliografia a respeito, abordando tanto as más condições de vida e trabalho, como a resistência dos negros escravizados no Brasil. Consultar, entre outras obras: MATTOSO, Kátia M. de Q. Ser escravo no Brasil. São Paulo: Brasiliense, 1982; CHALHOUB, Sidney. Visões da liberdade: uma história das últimas décadas da escravidão na corte. São Paulo: Cia. das Letras, 1990; TRINDADE, Etelvina. O trabalho nos engenhos. São Paulo: Atual, 1996; PINSKY, Jaime. Escravidão no Brasil. Ed. rev. ampl. São Paulo: Contexto, 2002. Sobre as condições de trabalho dos empregados domésticos, consultar: GRAHAM, Sandra L. Proteção e obediência: criadas e patrões no Rio de Janeiro (1860-1910). São Paulo: Cia. das Letras, 1992.

${ }^{11}$ Sobre a forma como o "problema racial" foi pensado no Brasil, na passagem da Monarquia para a República, consultar: ORTIZ, Renato. Cultura brasileira e identidade nacional. São Paulo: Brasiliense, 1985; 
SKIDMORE, Thomas E. Preto no branco: raça e nacionalidade no pensamento brasileiro. 2. ed. Rio de Janeiro: Paz e Terra, 1989; HERSCHMANN, Micael \& PEREIRA, Carlos A. M. A invenção do Brasil moderno: medicina, educação e engenharia nos anos 20-30. Rio de Janeiro: Rocco, 1994; SCHWARCZ, Lilia M. O espetáculo das raças: cientistas, instituições e questão racial no Brasil (1870-1930). São Paulo: Cia. das Letras, 1993.

${ }^{12}$ Citado por MORAIS, Frederico. Arte é o que eu e você chamamos arte: 801 definições sobre arte e o sistema de arte. Rio de Janeiro: Record, 1998, p. 136.

Artigo recebido em 02/2009. Aprovado em 06/2009. 